\title{
HEADACHE AND PSYCHIATRIC COMORBIDITIES: A RETROSPECTIVE STUDY IN A PORTUGUESE HEADACHE OUTPATIENT CLINIC
}

\author{
C. Fernandes Santos', E. Silva², A. Rachão², L. Pereira², M. Rodrigues² \\ ${ }^{1}$ Department of Psychiatry and Mental Health, Hospital Garcia de Orta - Almada, Portugal \\ 2 Department of Neurology, Hospital Garcia de Orta - Almada, Portugal
}

\section{OBJECTIVES}

To assess and characterize psychiatric comorbidities in patients referred to a Headache Outpatient Clinic ( $\mathrm{HOC})$.

\section{BACKGROUND}

Headache disorders, such as migraine and tension-type headache, and psychiatric disorders, such as anxiety and depression, are commonly found together among general populations worldwide.

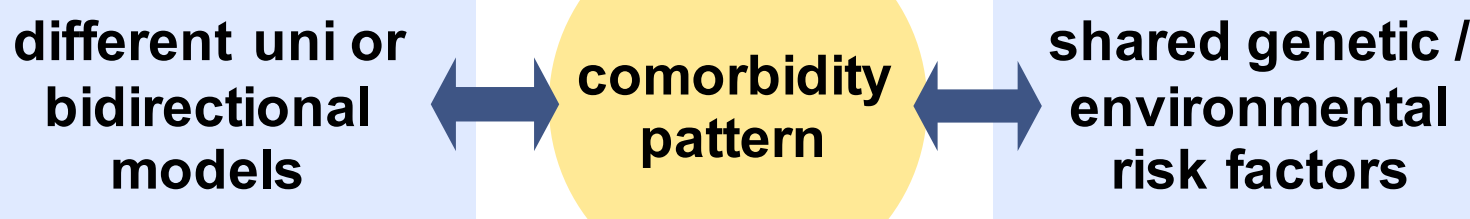

development of both clinical conditions

The coexistence of these entities worsens the clinical situation and increases the risk of chronicity and likelihood of treatment failure.

\section{MATERIALS AND METHODS}

From a sample of 167 patients with headache, referred to the HOC in Hospital Garcia de Orta (Portugal) between June, 2017 and February, 2019, a retrospective analysis was conducted, focusing on psychiatric comorbidities (International Classification of Diseases - 10th revision [ICD-10]) and concerning sociodemographic and clinical data.

\section{RESULTS}

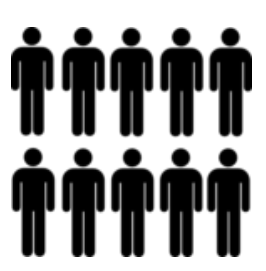

\section{7}

patients

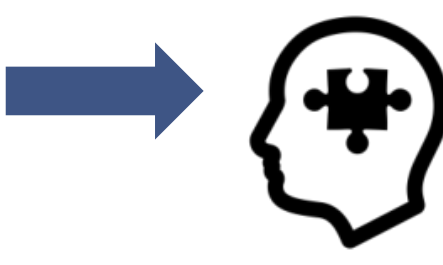

55

psychiatric

comorbidity

\section{PSYCHIATRIC DISORDER}

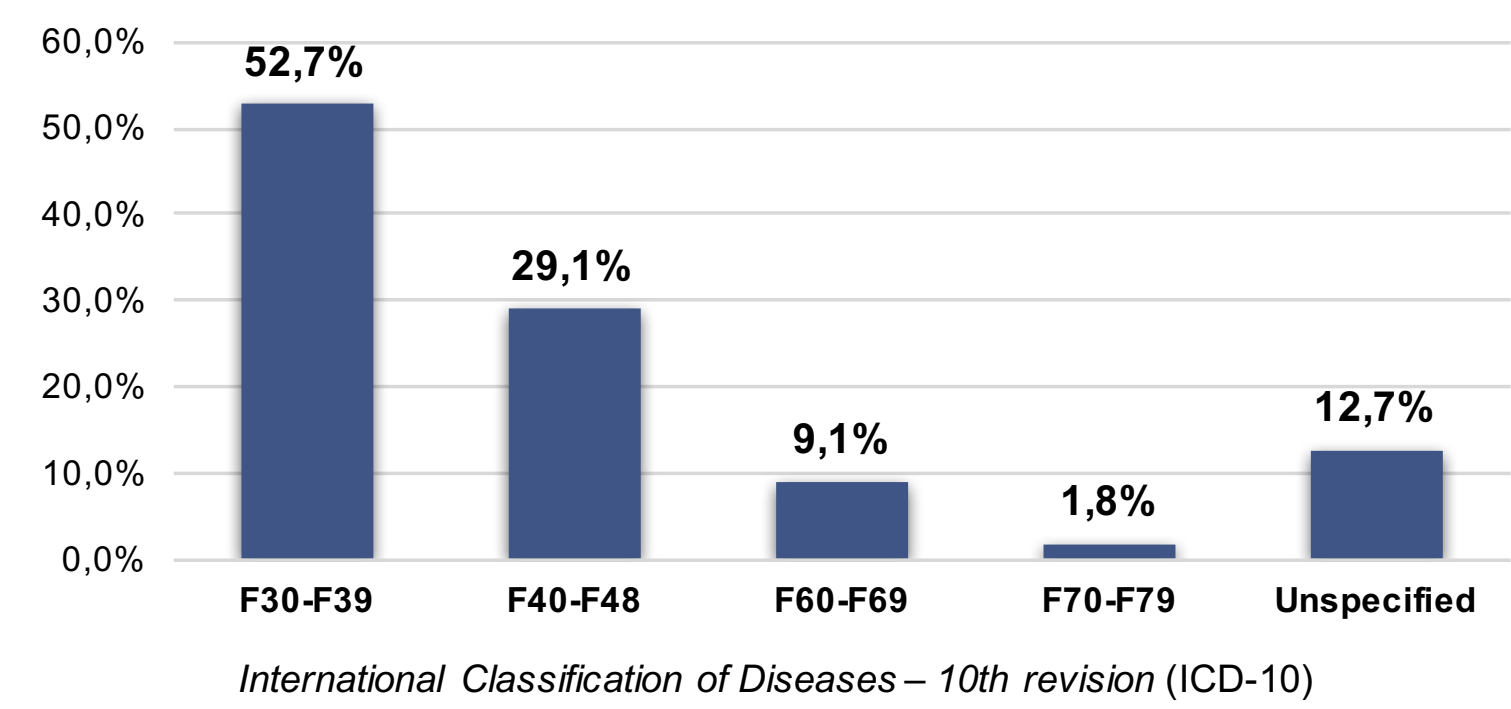

- Mood disorders are the most frequent category, followed by neurotic, stress-related and somatoform disorders, personality disorders and mental retardation;

- Three patients $(5.5 \%)$ had $>1$ psychiatric diagnosis;

- Only $29.1 \%$ were followed-up in a Psychiatry Consultation.

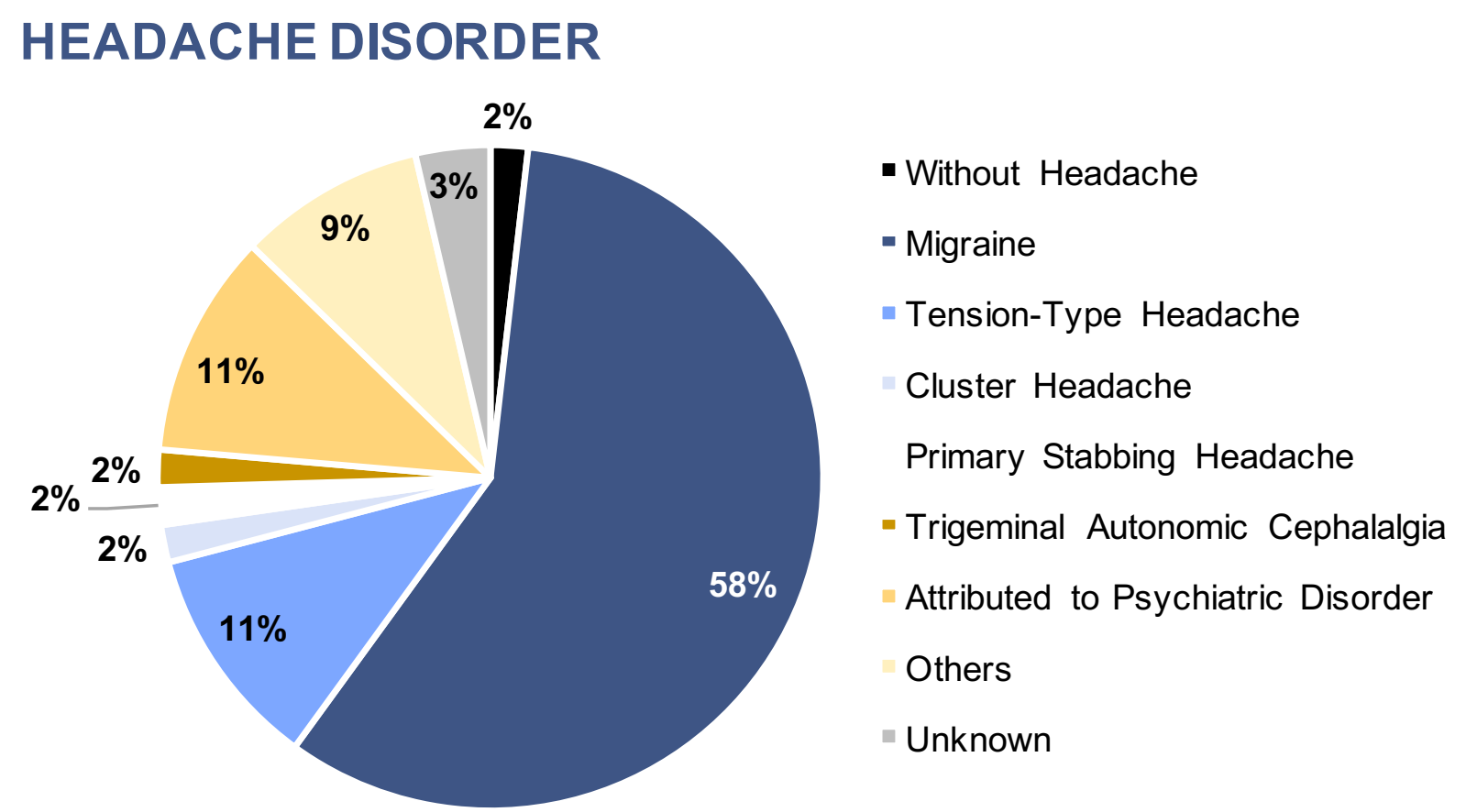

The International Classification of Headache Disorders 3rd (ICHD-3)

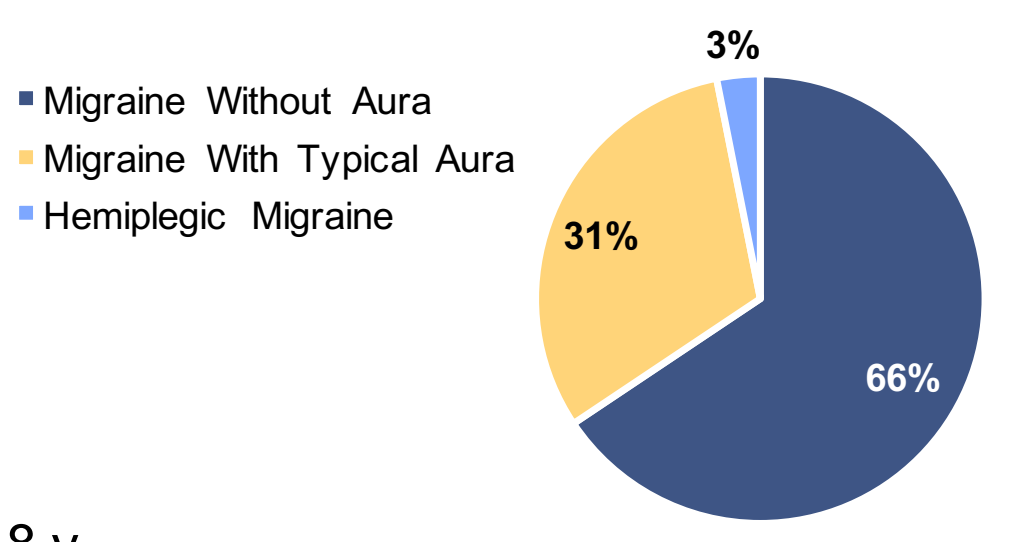

Duration of Disease

- Average|15.4 y

- Median | 11 y

- $\operatorname{Min} \mid 4$ mo; Max $\mid 48$ y

- Average monthly no. of days with headache | 15 days;

- Medication-overuse headache was present in $30.9 \%$ of patients.

\section{CONCLUSIONS}

Psychiatric comorbidities were found to be prevalent in our cohort of patients. Given the complexity of the clinical picture in cases of comorbidity, further studies are needed for the establishment of a proper and multidisciplinary intervention.

REFERENCES: 1. Bergman-Bock S. Associations Between Migraine and the Most Common Psychiatric Co-Morbidities. Headache. 2018 Feb;58(2):346-353. 2. Minen MT, Begasse De Dhaem O, Kroon Van Diest A, Powers S, Schwedt TJ, Lipton R, Silbersweig D. Migraine and its psychiatric comorbidities. J Neurol Neurosurg Psychiatry. 2016 Jul; 87(7):741-9. 3. Leo RJ, Singh J. Migraine headache and bipolar disorder comorbidity: A systematic review of the literature and clinical implications. Scand J Pain. 2016 Apr;11:136-145. 4. Risal A, Manand har K, Holen A, Steiner TJ, Linde M. Comorbidities of psychiatric and headache disorders in Nepal: implications from a nationwide population-based study. J Headache Pain. 2016;17:45. 5. Martins V, Temótio, J, Murta, I. Psychiatric Comorbidities Associated with Headaches: the Experience of the Liaison Consultation. Acta Med Port 2015 Jan-Feb;28(1):44-50. 6. Lake AE 3rd, Rains JC, Penzien DB, Lipchik GL. Headache and psychiatric comorbidity: historical context, clinical implications, and research relevance. Headache. 2005 May;45(5):493-506. 